\title{
EleCtromagnetic EMission Measurement OF DEVICES WITH GSM INTERFACE
}

\author{
Jozef Hallon, Mikuláš Bittera, René Hart’anský \& Karol Kováč
}
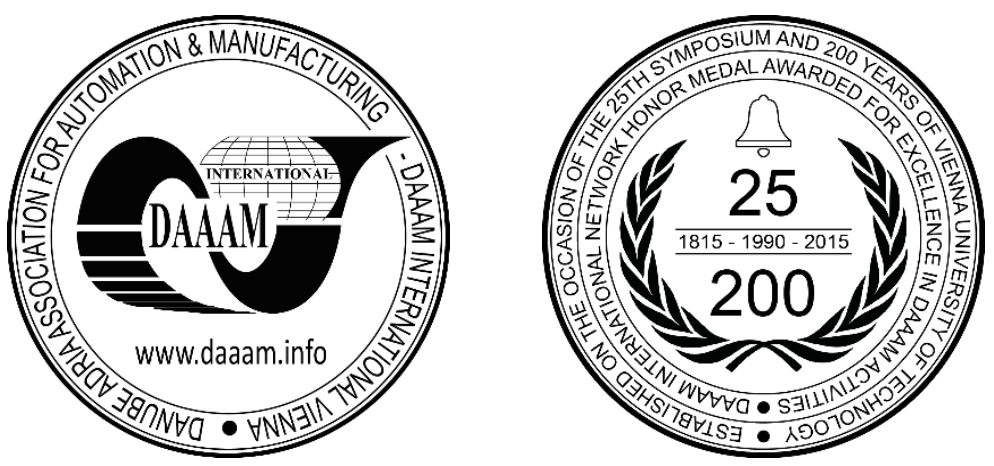

This Publication has to be referred as: Hallon, J[ozef]; Bittera, M[ikulas]; Hartansky, R[ene] \& Kovac, K[arol] (2016). Electromagnetic Emission Measurement of Devices With GSM Interface, Proceedings of the 27th DAAAM International Symposium, pp.0400-0404, B. Katalinic (Ed.), Published by DAAAM International, ISBN 978-3-90273408-2, ISSN 1726-9679, Vienna, Austria

DOI: $10.2507 / 27$ th.daaam.proceedings.059

\begin{abstract}
The paper deals with the methodology of measurements of conducted and radiated electromagnetic emissions of devices equipped with a GSM interface whereas their full functionality has to be maintained during the electromagnetic compatibility (EMC) measurement. At first it briefly describes a standard measurement method and an auxiliary system securing the GSM signal in a shielded semi-anechoic chamber, where the measurement takes place. Then it picks up the most important factor, which causes the rise of radiated emission level during GSM communication and it demonstrates the level of this emission increase. At the end the paper outlines to ways to suppress this phenomenon and analyses the circumstances by other wireless communication technologies.
\end{abstract}

Keywords: Electromagnetic compatibility; radiated emission; conducted emission; shielded chamber; GSM; GPRS.

\section{Introduction}

Wireless networks are increasingly used for transfer of information among technological devices: GSM network, serving primarily for voice services and its part GPRS, or its modified version - EDGE (has different modulation and coding) serving as mobile data networks, gained great popularity. GSM/GPRS interface became part of not only telecommunication devices, but also various telemetric, controlling and monitoring systems, e.g. [1], [2], [3], [4]. It is relatively outdated $2.5 \mathrm{G}$ technology, but it is still sufficient for many measurement systems.

Devices placed on the EU market must meet the requirement, that the electromagnetic (EM) interference they produce does not exceed the level, when radio and telecommunication devices or other devices cannot operate with the intended purpose [5]. Special measurement procedures standardized in relevant technical standards [6], [7] are used for detecting the levels of interference of electronic equipment. The requirement of the measurement procedure at measuring the EM emissions is that the device is to be measured in the mode, when its EM radiation is at the highest level [6]. Devices using GSM/GPRS (hereinafter only GSM) interface reach highest level of EM radiation when the GSM modem is in the broadcast mode. This is because the broadcast mode makes high energetic demands on the power supply system generally associated with higher levels of EM emissions.

The measurement of EM emissions is often carried out in shielded chambers specially adapted for this purpose. However the principle of the shielded chamber used for measurement of radiated EM emissions itself prevents the 
creation of a dataless connection. This requires modification of the measurement procedure and equipping the anechoic shielded chamber, where the measurements of EM emissions are carried out, with new equipment, allowing a wireless connection to outside network of assessed device data interface [8], [9].

Considering the mention facts we describe the standard emission (radiated as well as conducted) measurement setup with additional GSM communication equipment in the second part of the paper. In part 3 we analyse the main reason of emission increase during GSM communication, which is the rise of current supplying the electronic device containing GSM module. On a real device prototype we show the circuit elements, what may help to lower emissions. Then we present the comparison of emission measurement results of two operational modes of the device. Both emission spectra are shown to see the difference. The results are presented both for radiated as well as conducted emissions. The variances are described in the text.

\section{Measurement Setup}

The standard radiated emission measurement test setup requires that tested device (EUT - equipment under test) is placed on a supporting table or on the floor of the shielded chamber. The chamber is in a semi-anechoic configuration conducting metallic floor creates reflective plane. The measuring distance is $L=3 \mathrm{~m}$ or $10 \mathrm{~m}$ [6]. The antenna and the EUT form the two foci of imaginary ellipse, creating an obstruction-free area, which defines a minimum area free from scatterers of EM field. Technical equipment in the chamber must enable EUT to rotate around its axis and antenna to adjust the height in the range of $1 \div 4 \mathrm{~m}$ above a conductive floor of the chamber (Fig. 1a). The automated measuring system measures radiated emissions (antenna - preamplifier - measuring receiver, which is connected to the PC) at various positions of the EUT and the antenna. Then the system compares the measured emissions with the limit values given in the relevant standard [10].

GSM communication of the EUT requires creating a connection, which provides bidirectional data transmission between the EUT and auxiliary equipment situated outside the shielded chamber. GSM connection to the EUT needs a communication system (outside shielded chamber) consisting of GSM antenna and repeater that receives and amplifies signal of nearby base stations. This signal is transferred via coaxial cables and feed-through to the GSM antenna inside the chamber. The communication system is shown in Fig. 1b. Location of the GSM antenna inside the chamber and GSM signal level have to be chosen to enable tested device a reliable communication, while the measuring antenna should receive GSM signal of sufficiently low level (ideally less than relevant limit level, but definitely cannot exceed maximal input power of a measuring preamplifier). High level of signal can cause a malfunction of the measuring preamplifier and then a degradation of the measurement [9].

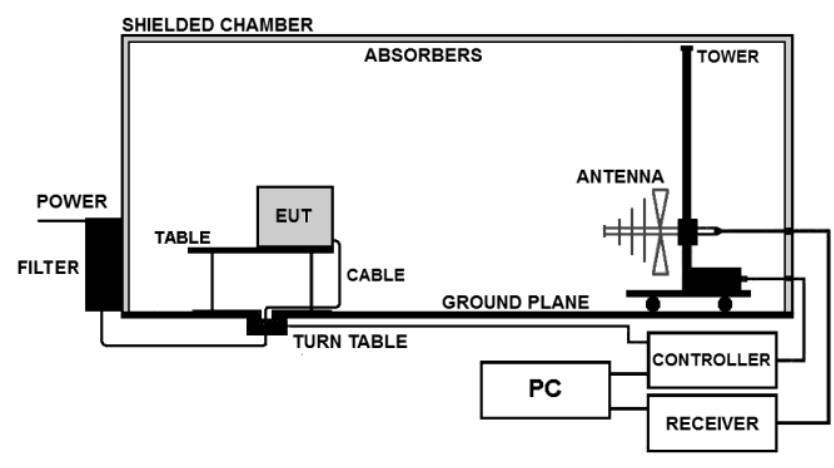

a)

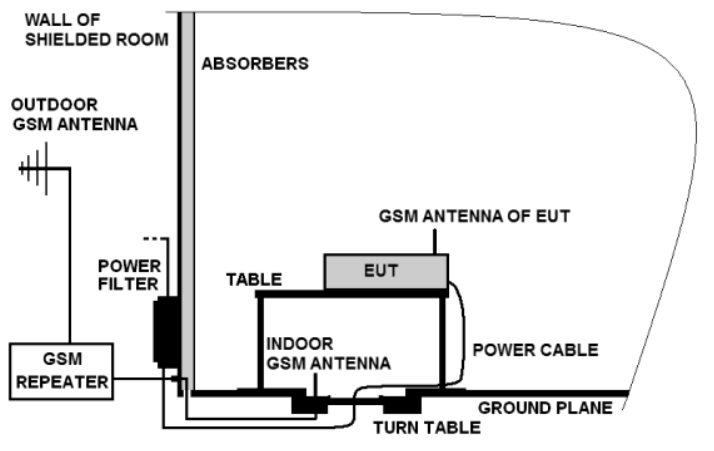

b)

Fig. 1. Test setup for measurement of radiated emissions (a) and GSM communication system (b)

In case of measuring a conducted interference (interfering terminal voltage) the situation is simpler. The measurements can be carried out with an open chamber, allowing normal GSM communication without the mentioned GSM communication system. Only the reference metal floor of the chamber and the supply system, filtered in order to prevent the interfering voltage from penetrating into the shielded chamber via the power supply system, is used for this measurement. Moreover the measurement of radiated emissions of the tested device is performed each time, the measurement of conducted emissions are performed only in case the EUT is connected to an external common AC or DC power distribution or to telecommunication ports. The measurement of emitted disturbance voltages on the power terminals is performed using the LISN (Line Impedance Stabilizing Network). LISN is connected to the measuring receiver (more details are in [6]).

\section{Analysis of Cause of Emission Increase during GSM Communication}

During operation the current consumed by the GSM modem may differ by several orders of magnitude. During the broadcasting interval the peak current may reach up to $3 \mathrm{~A}$. The amount of this current is proportional to radiated power. The power is proportional to the distance from the base station, dimming of transmission path (e.g. a building) 
and depends also on properties of the antenna connected to the modem. The Fig. 2 shows the time dependence of the modem current consumption (in GPRS mode) for typical operating modes for modem MC75i [11], [12]. Shown maximal impulse current due to impedances in power circuits ((impedance/resistance on connectors, in the power source and signal tracks) causes the pulse fluctuations of power voltage and transitory phenomenon on pulse edges (Fig. 2). Decreases of power voltage may reach up to several $100 \mathrm{mV}$ (for typical modem power voltage $3.2 \mathrm{~V}-4.5 \mathrm{~V}$ ). This makes high demands on the construction of modem power circuits. In case mistakes are made in the design and realization of power circuits, it has an adverse consequence on the EMC properties of the whole device.

We have more alternatives when powering the device containing GSM modem. If it is a portable device, batteries or rechargeable batteries are used. When the external voltage is small, e.g. $5 \mathrm{~V}$, low drop linear stabilizers are used. Switching regulators are used for higher power voltages, where the linear regulators would be inefficient from the energetic point of view. In terms of EMC this alternative is the most interesting one, because the switching regulator itself produces relatively high broad spectrum interference further augmented by the impulse load of GSM modem.

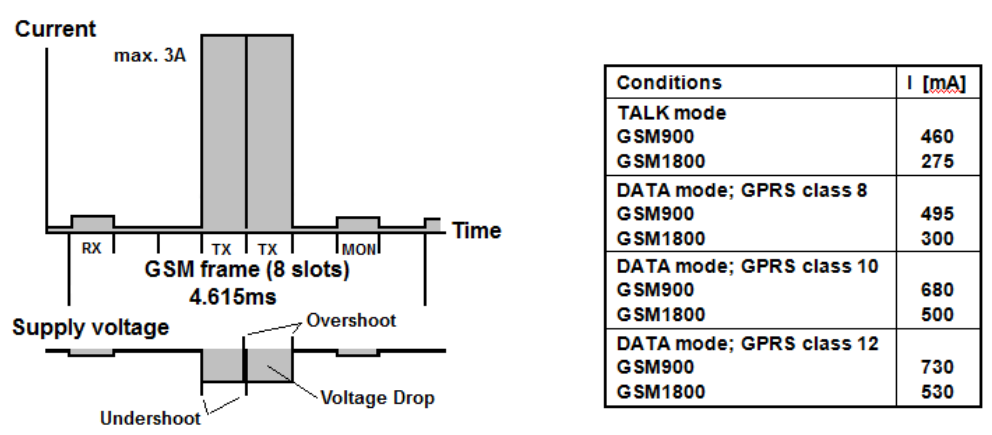

Fig. 2. Time dependence of supply current, voltage and maximal average supply current of modem MC75i.

The capacitor with high capacity, which must cover the power supply of the modem at the peak current during transmission slot (slots) within the GSM frame, has a vital role in the power supply chain. It must be a low ESR (Equivalent Series Resistance) type with values of the order of $10 \mathrm{~m} \Omega$ and sufficient capacity. The required capacity changes depending on the type of stabilization circuits and ranges from $100 \mu \mathrm{F}-10 \mathrm{mF}$ [11]. Chosen capacitor must be accompanied with a parallel combination of several ceramic condensers (e.g. $100 \mathrm{nF}+10 \mathrm{nF}+100 \mathrm{pF}$ ) to reduce the EMI (electromagnetic interference) in the wide frequency range. These elements must be located in the immediate vicinity of the GSM modem; otherwise their effect will not be as expected [13].

As already mentioned the use of switching DC/DC converter is the most difficult solution in terms of emissions minimization, however in terms of efficiency it is often necessary (power from $12 \mathrm{~V}$ or $24 \mathrm{~V}$ distribution systems). There is a large number of converters manufactured by various companies available. It is necessary to follow wiring diagram prescribed by the manufacturer and ensure an efficient EMI input filter on the supply side. The Fig. 3 shows a block diagram of power circuits mentioned above.

It is very important to pay great attention to the layout of individual components and PCB design for power circuits and respect recommendations of the manufacturer of the DC/DC converter, GSM modem and general construction rules known from the EMC literature [13].

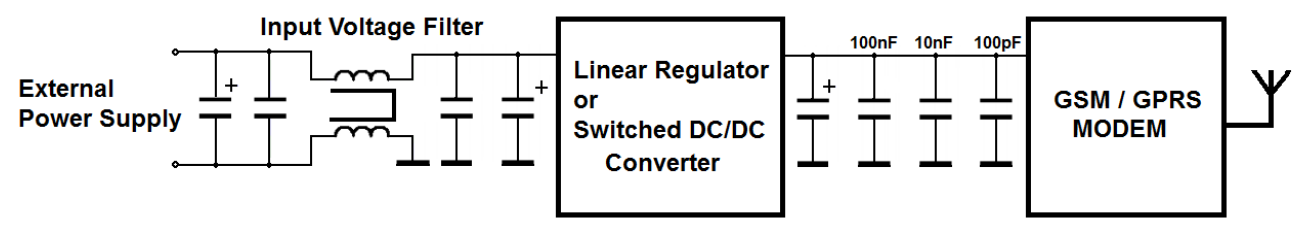

Fig. 3. Scheme of power circuits of GSM modem.

\section{Example of Emission Measurement}

We performed the measurement on the prototype system sample of the data logger for remote data collection equipped by the GSM modem. The sample had deliberately undersized filter measures as well as the value of the condenser with low ESR for coverage of energy consumption during transmission slots, so that the difference in emission level between the state of the GSM modem in standby mode and operational mode (the modem was broadcasting a data packet with rate of 500 Bytes/s, or was alternately sending a SMS continuously) was significant. The device consisted of a GSM modem MC75i, powered by the step-down DC/DC converter from a $12 \mathrm{~V}$ battery. The device measured voltage values using an A/D converter controlled by a microcontroller and concurrently the task of the converter was to format measured data and send it to the modem. The device was situated on one circuit board and it 
was located in a plastic box. The analog input cable was shielded, it was $1 \mathrm{~m}$ long and it ended with typical impedance. The modem output cable was shielded as well, it was $0.5 \mathrm{~m}$ long and a GSM antenna (short monopole) was connected to the end of the cable. Power cable (wire pair) leading to the battery was $30 \mathrm{~cm}$ long. In order to force the modem work under more difficult conditions, i.e. at a low level of signal from the base station, we connected a $20 \mathrm{~dB}$ attenuator to the GSM repeater output. This way the modem worked at the edge of its capabilities, in the worst possible situation.
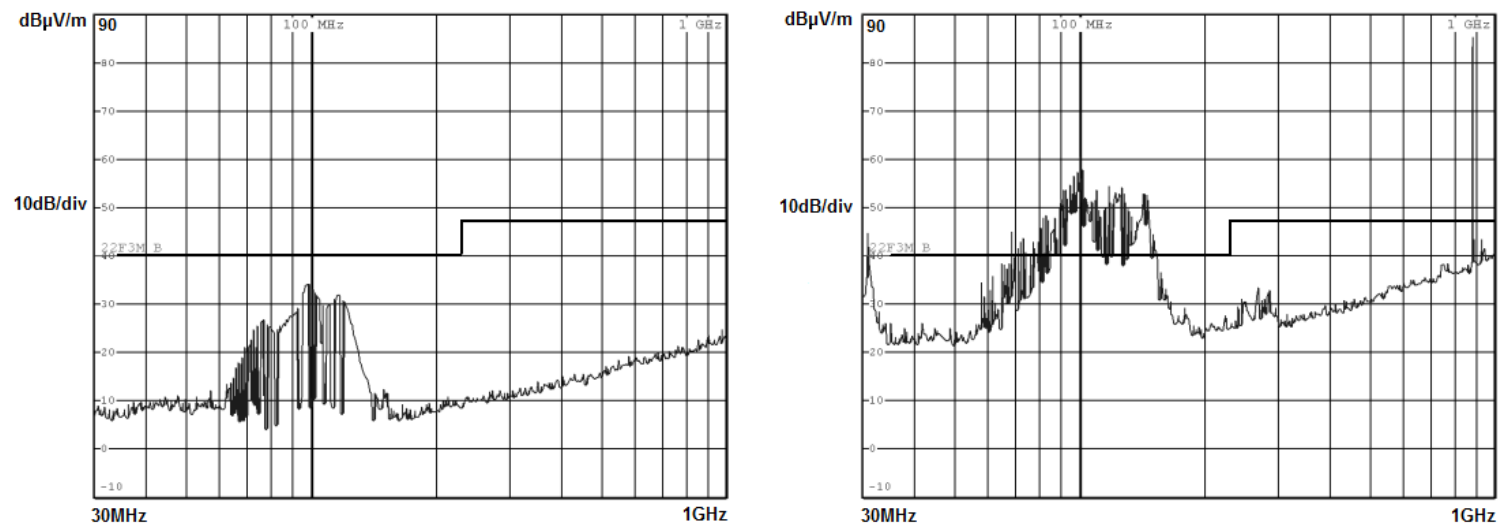

Fig. 4. Radiated emission of remote measuring system with GSM modem (without the GPRS transmission and with GPRS transmission)

Radiated emissions were measured in the frequency range $30 \mathrm{MHz}-1 \mathrm{GHz}$, with the residual bandwidth (RBW) of $120 \mathrm{kHz}$, as prescribed in technical standards, which deal with measurement of EM emissions of devices information technology. The limit was chosen for the emission class B (for measuring distance of $3 \mathrm{~m}$ ) [6].

A high peak, corresponding to the modem working frequency appeared near $900 \mathrm{MHz}$ in case of active operation of the GSM modem. The radiated power was relatively high; therefore we needed to attenuate the input signal of the measuring receiver by $20 \mathrm{~dB}$ (to avoid overloading of electronic circuits of the measuring receiver). This was reflected in rising of the apparatus noise level. As shown in Fig. 4 on the right, in case the modem was operational, emissions increased by approximately $25 \mathrm{~dB}$ and moreover in the range from $80 \mathrm{MHz}-150 \mathrm{MHz}$ significantly exceeded the limit. Even though the spectrum was measured using an peak detector and the limit is determined for measurement by a quasipeak (QP) detector, the limit would be exceeded even in the case of measurements by individual peaks with a QP detector (it would be unbearably time consuming to measure the whole spectrum using a QP detector). It is unpleasant even due to the fact that VHF bandwidth for radio is located in this frequency range and higher level of emissions in this area may interfere with the radio reception.
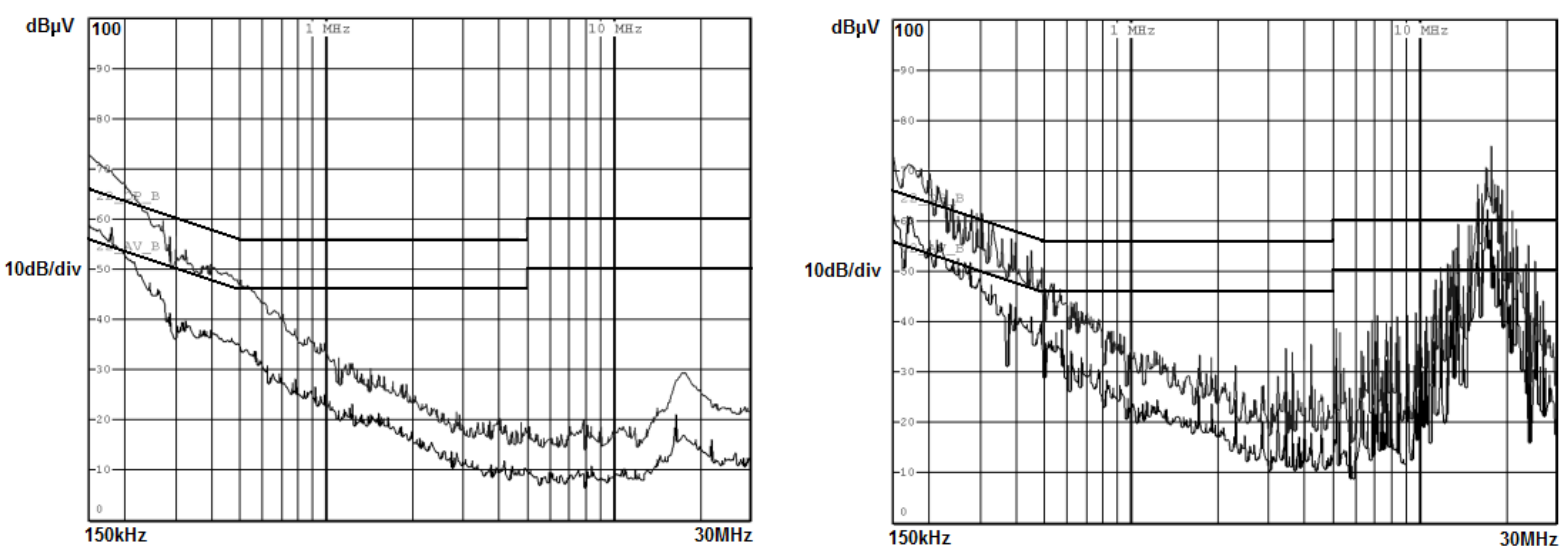

Fig. 5. Conducted emission remote measuring system with GSM modem (without using the GPRS activities and with enabled GPRS activities)

Conducted emissions from power supply were measured in the frequency range $150 \mathrm{kHz}-30 \mathrm{MHz}$, at intermediate frequency bandwidth of $9 \mathrm{kHz}$, as prescribed in technical standards dealing with measurements of emissions of devices of information technology. The limit was again chosen for the emission class B [6]. Even in this case we can see a significant difference in the emission spectrum at active modem operation (Fig. 5 on the right). The most significant interference appears in range $15 \mathrm{MHz}-25 \mathrm{MHz}$, where the values exceed relevant limits by approx. $10 \mathrm{~dB}$. Even in this case there will be a problem with measurement using QP and also AV detector, because they would exceed the relevant limits. 


\section{Conclusion}

We showed in the paper the significance of emissions levels increase when changing the mode of operation of electronic device with GSM communication module from quiet to transmit operation. For our example of such device this rising achieved $+25 \mathrm{~dB}$ for radiated and even more than $+40 \mathrm{~dB}$ for conducted emissions. It is necessary to mention that studied device was not perfectly designed as our aim was to demonstrate the significance of the GSM transmission operation influence upon the level of emissions of both types. On the basis of this reality one must conclude that within EMC compliance verification procedure it is necessary to measure each electronic device with GSM communication possibilities also during GSM communication operation.

The measurement of radiated emissions of mentioned devices itself requires additional equipping of semi-anechoic shielded chamber with a system ensuring the optional GSM operation. Such system is also needed for immunity to EM field testing. Many EMC laboratories do not have such facilities, so they are not able to ensure GSM data transfer during EMC measurements, and therefore in many cases the measurement could not be carried out in transmitting mode (typical operation mode).

As was demonstrated in the paper the higher level of emissions is caused by higher power supply currents consumed by powerful GSM transmitter output amplifier. It is because this type of communication required up to $2 \mathrm{~W}$ of high frequency power. Other wireless data communication systems, e.g. WIFI (the maximum output of $100 \mathrm{~mW}$ is allowed in Europe for bandwidth of $2.4 \mathrm{GHz}$ ) and Bluetooth (by classes $1 \mathrm{~mW}-100 \mathrm{~mW}$ ) work with the order of less output power. So one may predict, that unintended radiation of these devices would be under limits of corresponding EMC standards.

\section{Acknowledgments}

Work presented in this paper was supported by the Slovak Grant Agencies of Ministry of Education, Science, Research and Sport of the Slovak Republic VEGA No. 1/0431/15 and KEGA No.016STU-4/2014, and Slovak Research and Development Agency APVV, No. APVV-15-0062.

\section{References}

[1] Angelides, K. (2013). Controlling diabetes with a cellular GPRS linked glucometer pedometer, Patent US8568309 B2, 29. 10. 2013

[2] Jayakumar, J.; Queen, J. H. J.; James, T.; Hemalatha, G. \& Lonappan, N. (2013). Distribution Transformer Monitoring Using GPRS. International Journal of Scientific \& Engineering Research, Volume 4, Issue 6, June2013, ISSN 2229-5518, pp. 1199-1204

[3] Korhonen, J.; Aalto, O.; Gurtov, A. \& Lamanen, H. (2001). Measured performance of GSM, HSCSD and GPRS, Proceedings of Communications ICC 2001, IEEE International Conference on, Helsinki, 11 Jun 2001-14 Jun 2001, ISBN: 0-7803-7097-1, pp. 1330-1334

[4] Bordea, N.; Sintea, S.; Moraru, S.A. \& Kristaly, D.M. (2008). Serial Data Communication Connection Over GSM Data Channel, Annals of DAAAM for 2008 \& Proceedings of the 19th International DAAAM Symposium, 2225th October 2008, Trnava, Slovakia, ISSN 1726-9679, ISBN 978-3-901509-68-1, Katalinic, B. (Ed.), pp. 01270128, Published by DAAAM International Vienna, Vienna

[5] Directive 2014/53/EU of the European Parliament and ot the Council of 16 April 2014 on the harmonisation of the laws of the Member States relating to the making available on the market of radio equipment, Official Journal of the EU, L 153/62-105, 22. 5. 2014, Available from: http://eur-lex.europa.eu/legal-content/HR/ALL/?uri=CELEX: 32014L0053

[6] European standard EN55022:2010 Information technology equipment - Radio disturbance characteristics - Limits and methods of measurement, CENELEC 2010

[7] European standard EN55032:2015 Electromagnetic compatibility of multimedia equipment - Emission requirements, CENELEC 2015

[8] Hallon, J.; Hart'anský, R. \& Bittera M. (2015). Testing EMC properties of electrical devices equipped wireless communication, Proceedings of the 10th International Conference on Measurement. Smolenice, Slovakia, 25.-28. 5. 2015, ISBN: 978-80-969672-9-2, pp. 249-252

[9] Hallon, J.; Bittera, M. \& Kováč, K. (2016). The interface set for the EMC testing shielded chamber. Przeglad elektrotechniczny, R. 92 NR 2/2016, ISSN: 0033-2097, pp. 31-33

[10] Cicakova, O.; Szolik, I. \& Krammer, A. (2009). Complex system for EMC immunity tests, Proceedings of Applied Electronics 2009, Pilsen, Czech Republic, 9.-10. 9. 2009, ISSN: 1803-7232, ISBN: 978-80-7043-781-0, pp. 87-90

[11] Power Supply for Wireless Applications, Appl. Note 26, WM_AN26_PwrSupply_v06 2013-12-13, Available from: https://developer.gemalto.com/sites/default/files/wm_an_26_pwr_supply_v06.pdf

[12] Quad-band GSM/GPRS data \& voice modules System Integration Manual, 22. 8. 2014, Available from: https://www.u-blox.com/sites/default/files/products/documents/LEON-G1_SIM_(UBX-13004888).pdf

[13] Goedbloed, J. (1992). Electromagnetic Compatibility, Prentice Hall, ISBN: 0-13249293-8, New Jersey 